\title{
Commentary: Risk of aortic intervention after type B dissection-You cannot win unless you keep score
}

\author{
Charles M. Wojnarski, MD, MS
}

\author{
From the Division of Cardiovascular and Thoracic Surgery, Department of Surgery, Duke University Medical \\ Center, Duke University, Durham, NC \\ Disclosures: Author has nothing to disclose with regard to commercial support. \\ Received for publication Aug 4, 2019; accepted for publication Aug 5, 2019; available ahead of print Oct 22, \\ 2019. \\ Address for reprints: Charles M. Wojnarski, MD, MS, Duke University Medical Center, 2301 Erwin Rd, Durham, \\ NC 27710 (E-mail: charles.wojnarski@ duke.edu). \\ J Thorac Cardiovasc Surg 2020;159:2187-8 \\ $0022-5223 / \$ 36.00$ \\ Copyright (c) 2019 by The American Association for Thoracic Surgery \\ https://doi.org/10.1016/j.jtcvs.2019.08.050
}

In this issue of the Journal, Matsushita and colleagues ${ }^{1}$ present a thoughtful and sophisticated analysis of risk factors for late aortic events in patients after uncomplicated type $\mathrm{B}$ dissection. They identified a cohort of patients at 2 institutions who presented with uncomplicated acute type B dissection and performed a multivariable competing risk Fine-Gray regression model to determine risk factors for late aortic events. They then created a simple scoring system to identify patients at high and low risk of future events and externally validated this score in a 4-center cohort of similar patients.

In this study, a late aortic event was defined as open surgery or thoracic endovascular aneurysm repair that occurred after discharge from initial hospitalization for acute type B dissection. To be clear, the indication for operation was aneurysmal degeneration of the descending aorta in almost all cases, save that of 1 patient who developed an acute retrograde type A dissection.

The 4 risk factors identified for descending aortic aneurysmal degeneration requiring intervention were as follows:

1. Initial aortic diameter of at least $40 \mathrm{~mm}, 2$ points (Hazard ratio [HR], 4.11; 95\% Confidence interval [CI], 2.34-7.20; $P<.01)$

2. False lumen larger than true lumen, 2 points (HR, 4.21; 95\% CI, 2.29-7.74; $P<.01$ )

3. Ulcerlike projection, 1 point (HR, 2.10; 95\% CI, 1.16-3.49; $P=.01$ )

4. Age of at least 70 years, 1 point (HR, 1.92; 95\% CI, 1.17-3.17; $P=.01$ )

Patients with 0 points or 1 point were considered to be at low risk, whereas those with at least 2 points were identified as being at high risk by means of receiver operating characteristic analysis, with an area under the curve of 0.83 $(P<.001)$ indicating $83 \%$ accuracy of the scoring system in identifying high and low-risk patients with a cutoff of

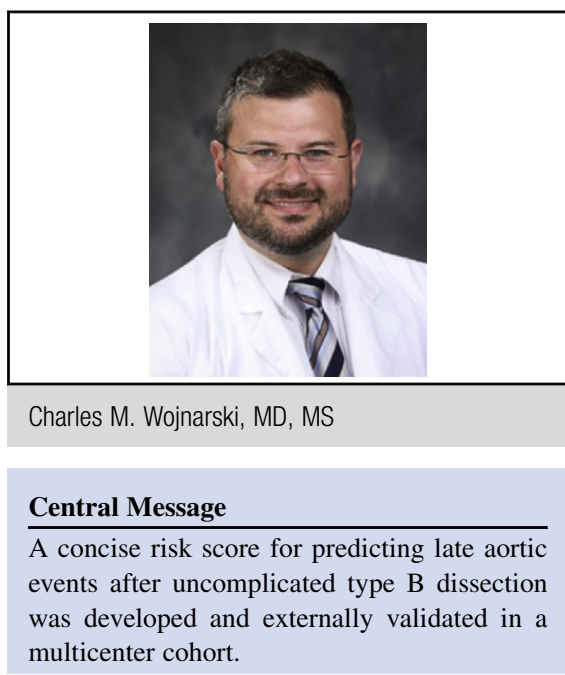

See Article page 2173.

at least 2 points. The translation of HRs to point values makes sense in the setting, because the estimates are very close to integer multiples of each other-Matsushita and colleagues ${ }^{1}$ had a little bit of luck here.

Indeed, the score validated well in the second cohort of patients analyzed (area under the curve. $0.85 ; P<.001$ ), and the cutoff of at least 2 points proved to be extremely clinically relevant, with 3 -year event rates of $0.9 \%$ in the low-risk group and $47.1 \%$ in the high-risk group $(P<.0001)$. This large absolute difference in outcome over time is the strongest evidence that this is indeed a clinically and statistically relevant scoring system to predict descending aortic aneurysmal degeneration requiring late intervention in patients with uncomplicated type B dissection. Furthermore, the risk factors fall in line with multiple previously published series on the topic. ${ }^{2,3}$

But what do we do with this information? Why does this matter? In the immediate setting, this information can be used to guide surveillance intervals in patients with uncomplicated type B dissection. It is clear that all patients with type B dissection need to be followed up with regular clinical and radiologic surveillance, but these data can be used to help clinicians determine which patients might need more frequent or less frequent examinations.

In the long-term, this risk scoring system can be used to identify a cohort of high-risk patients whom could be enrolled in a prospective, randomized, controlled trial to 
finally answer the question of whether high-risk patients with uncomplicated type B dissection should undergo prophylactic thoracic endovascular aneurysm repair. Both INSTEAD (Investigation of Stent Grafts in Aortic Dissection) and ADSORB (Acute Dissection Stent Grafting or Best Medical Treatment) trials enrolled all comers, not just high-risk patients. In INSTEAD, the primary end point was all-cause mortality; in ADSORB, the primary composite end point was incomplete or no false-lumen thrombosis, aortic dilatation, or aortic rupture at 1 year, which was chosen to increase the primary event rate so that sample size could be manageable. ${ }^{4,5}$ It is hard to interpret and compare the results of these 2 trials given the primary end points what were chosen. Furthermore, a recent systematic review by Famularo and colleagues ${ }^{6}$ shows that it is still unclear whether early thoracic endovascular aneurysm repair truly prevents late aneurysmal degeneration of type $\mathrm{B}$ dissection.

It seems that in their current article, Matsushita and colleagues ${ }^{1}$ have identified a subset of patients at high-risk for aneurysmal degeneration of uncomplicated type B dissection-a subset that should be studied further. Through a colossal amount of sophisticated analysis, they have defined the inclusion criteria and set the stage for a well powered, randomized, controlled trial that may finally give us and our patients answers to the questions we are asked every day.

\section{References}

1. Matsushita A, Tabata M, Mihara W, Shimamoto T, Komiya T, Takanashi S, et al. Risk score system for late aortic events in patients with uncomplicated type B aortic dissection. J Thorac Cardiovasc Surg. 2020;159: 2173-83.e1.

2. Kamman AV, Brunkwall J, Verhoeven EL, Heijmen RH, Trimarchi S, ADSORB Trialists. Predictors of aortic growth in uncomplicated type B aortic dissection from the Acute Dissection Stent Grafting or Best Medical Treatment (ADSORB) database. J Vasc Surg. 2017:65:964-71.

3. Kudo T, Mikamo A, Kurazumi H, Suzuki R, Morikage N, Hamano K. Predictors of late aortic events after Stanford type B acute aortic dissection. J Thorac Cardiovasc Surg. 2014;148:98-104.

4. Nienaber CA, Kische S, Rousseau H, Eggebrecht H, Rehders TC, Kundt G, et al; INSTEAD-XL trial. Endovascular repair of type B aortic dissection: long-term results of the randomized investigation of stent grafts in aortic dissection trial. Circ Cardiovasc Interv. 2013;6:407-16.

5. Brunkwall J, Kasprzak P, Verhoeven EL, Heijmen R, Taylor P, ADSORB Trialists. Endovascular repair of acute uncomplicated aortic type B dissection promotes aortic remodelling: 1 year results of the ADSORB trial. Eur J Vasc Endovasc Surg. 2014;48:285-91.

6. Famularo M, Meyermann K, Lombardi JV. Aneurysmal degeneration of type B aortic dissections after thoracic endovascular aortic repair: a systematic review. J Vasc Surg. 2017;66:924-30. 